\title{
A NEW SPECIES OF IXODES (ACARI: IXODIDAE) FROM SOUTH AFRICAN MAMMALS
}

\author{
Dmitry A. Apanaskevich, Ivan G. Horak ${ }^{\star}$, Conrad A. Matthee $†$, and Sonja Matthee $\ddagger$ \\ United States National Tick Collection, the James H. Oliver, Jr. Institute of Arthropodology and Parasitology, Georgia Southern University, \\ Statesboro, Georgia 30460-8056. e-mail: dapanaskevich@georgiasouthern.edu
}

\begin{abstract}
A new tick species belonging to the African subgenus Afrixodes Morel, 1966, namely, Ixodes (Afrixodes) fynbosensis n. sp., is described. The female of $I$. fynbosensis is easily differentiated from the other African Ixodes species by a large, tapering triangular ventrolateral spur on palpal segment I. Nymph and larva of I. fynbosensis can be distinguished from those of other members of Afrixodes by a combination of the following characters: pointed hypostome, long auriculae, long and acute ventrolateral projections of basis capituli of nymph, only 2 pairs of central dorsal setae, and a straight posterior margin of scutum of the larva. Cytochrome oxidase I mtDNA sequence comparisons between I. fynbosensis and 10 other Ixodes Latreille, 1795, species support the recognition of this taxon as genetically distinct $(>13 \%$ corrected sequence divergences separate it from the remainder of the 10 recognized species used in this study), and preliminary phylogenetic analyses reveal that this taxon is most closely related to the southern African Ixodes pilosus Koch, 1844, and Ixodes rubicundus Neumann, 1904. Ixodes fynbosensis is known only from South Africa, where females have been collected from a domestic dog and a rodent, Rhabdomys pumilio (Sparrman), and nymphs and larvae have been collected from $R$. pumilio and unidentified shrews belonging to the Soricidae. Sequences generated for both nymphs and adult individuals were identical, confirming the correlation between the described life stages.
\end{abstract}

There are currently approximately 60 species in the subgenus Afrixodes Morel, 1966, of the genus Ixodes Latreille, 1795 (Clifford et al., 1973; Camicas et al., 1998). Many of these species have been inadequately studied, and several are known only from a few specimens or a single female. The larva and nymph have been described for only 12 species, only the nymph of another 5 , and only the larva of a further 4 species. Camicas et al. (1998) stated that the nymph and larva of Ixodes nairobiensis Nuttall, 1916, and of Ixodes rasus Neumann, 1899, and larva of Ixodes lewisi Arthur, 1965, had been described, but we could not find references to substantiate this assertion.

The diagnostics of the African Ixodes species are in many respects complicated, mainly because several of the descriptions of adults and those of the majority of the immature stages are in essence too schematic (Arthur, 1965). Because of this, it is very difficult to trace relationships between the species in the Afrixodes subgenus.

A new species belonging to this subgenus of Ixodes has recently been discovered in the southwestern Fynbos biome in South Africa, and the female and both immature stages are described here. Mitochondrial DNA data were used to authenticate the description and the association between the nymphs and adult individuals. All stages parasitize a species of murid rodent, some females infested a domestic dog, and the larvae and nymphs also infest shrews belonging to the Soricidae.

\section{MATERIALS AND METHODS}

The material examined for the description of the taxon is summarized in Table I. Only field-collected ticks were studied. The association between the stages has been made by means of morphological and molecular analyses and indirect data. The specimens that were examined are deposited in the United States National Tick Collection (USNTC) (James

Received 16 October 2009; revised 13 January 2010; accepted 21 January 2010.

* Department of Veterinary Tropical Diseases, Faculty of Veterinary Science, University of Pretoria, Onderstepoort, 0110, South Africa; and Department of Zoology and Entomology, University of the Free State, Bloemfontein, 9301, South Africa.

$\dagger$ Evolutionary Genomics Group, Department of Botany and Zoology, P/ bag X1, University of Stellenbosch, Matieland, 7602, South Africa.

tDepartment of Conservation Ecology and Entomology, P/bag X1, University of Stellenbosch, Matieland, 7602, South Africa.

DOI: 10.1645/GE-2366.1
H. Oliver, Jr. Institute of Arthropodology and Parasitology, Georgia Southern University, Statesboro, Georgia) and I. G. Horak tick collection (IGHTC) at the Department of Veterinary Tropical Diseases (Faculty of Veterinary Science, University of Pretoria, Onderstepoort, South Africa). Some of the paratypes will be deposited in the collections of the Zoological Institute, Russian Academy of Sciences (St. Petersburg, Russia), and the Gertrud Theiler Tick Museum of the Onderstepoort Veterinary Institute (Onderstepoort, South Africa).

The female and the immature stages were mounted on glass slides and examined using light microscopy; the female was also examined using stereomicroscopy. The spiracular plates of the nymph were studied using scanning electron microscopy. The spiracular plates of the female have not been illustrated to reduce the chances of damaging the specimens. Measurements for the female are given in millimeters $(\mathrm{mm})$, and those for the immature stages in micrometers $(\mu \mathrm{m})$. The measurements are arranged as follows: minimum-maximum (average; $\mathrm{n}=$ number of specimens measured).

The molecular research was based on an analyses of $600 \mathrm{bp}$ of 7 Ixodes COI mtDNA sequences obtained from Genbank (Ixodes turdus Nakatsuji, 1942: AB231668; Ixodes acutitarsus (Karsch, 1880): unpublished AB105166; Ixodes ovatus Neumann, 1899: AB231670; Ixodes vespertilionis Koch, 1844: AB231667; Ixodes pavlovskyi Pomerantzev, 1946: AB231669; Ixodes granulatus Supino, 1897: AB231673; Ixodes monospinosus Saito, 1968: AB231672; Mitani et al., 2007) and 5 additional newly generated sequences (Ixodes rubicundus Neumann, 1904: GU437875, Ixodes pilosus Koch, 1844: GU437874, Ixodes bakeri Arthur \& Clifford, 1961: GU437873, Ixodes fynbosensis n. sp. adult: GU437876, and Ixodes fynbosensis nymph with an identical sequence to the adult) obtained from the IGHTC. Total genomic DNA was extracted using standard procedures as specified by the DNeasy Kit (Qiagen, Hilden, Germany), and standard PCR was performed using the LCO1490 and HCO2198 primers as published by Folmer et al. (1994). BigDye (Applied Biosystems, Foster City, California) chemistry was used for sequencing, and sequences were manually aligned. GTR-corrected sequence divergence values and phylogenetic reconstruction (parsimony searches) were performed in PAUP*4b10 (Swofford, 2002).

\section{DESCRIPTION}

\section{Ixodes (Afrixodes) fynbosensis n. sp.} (Figs. 1-7)

Female (Figs. 1-2): Idiosoma (Figs. 1, 2A): Sub-oval, widest at level of spiracular plates; length from scapular apices to posterior body margin $2.26-2.42$, breadth $1.32-1.42,1.70-1.71 \times$ as long as broad (1 unengorged and 1 slightly engorged specimens measured). Scutum (Fig. 1): Long, outline broadly rounded, length 1.54-1.64, width 0.98 $1.02,1.57-1.61 \times$ as long as broad. Lateral carinae distinct, divergent, not reaching posterior margin; cervical grooves indistinct, superficial. Punctations very small and shallow, evenly distributed over scutum. Setae numerous and moderately long, some slightly shorter than those on alloscutum; distributed as figured. Alloscutum (Fig. 1): As illustrated. 


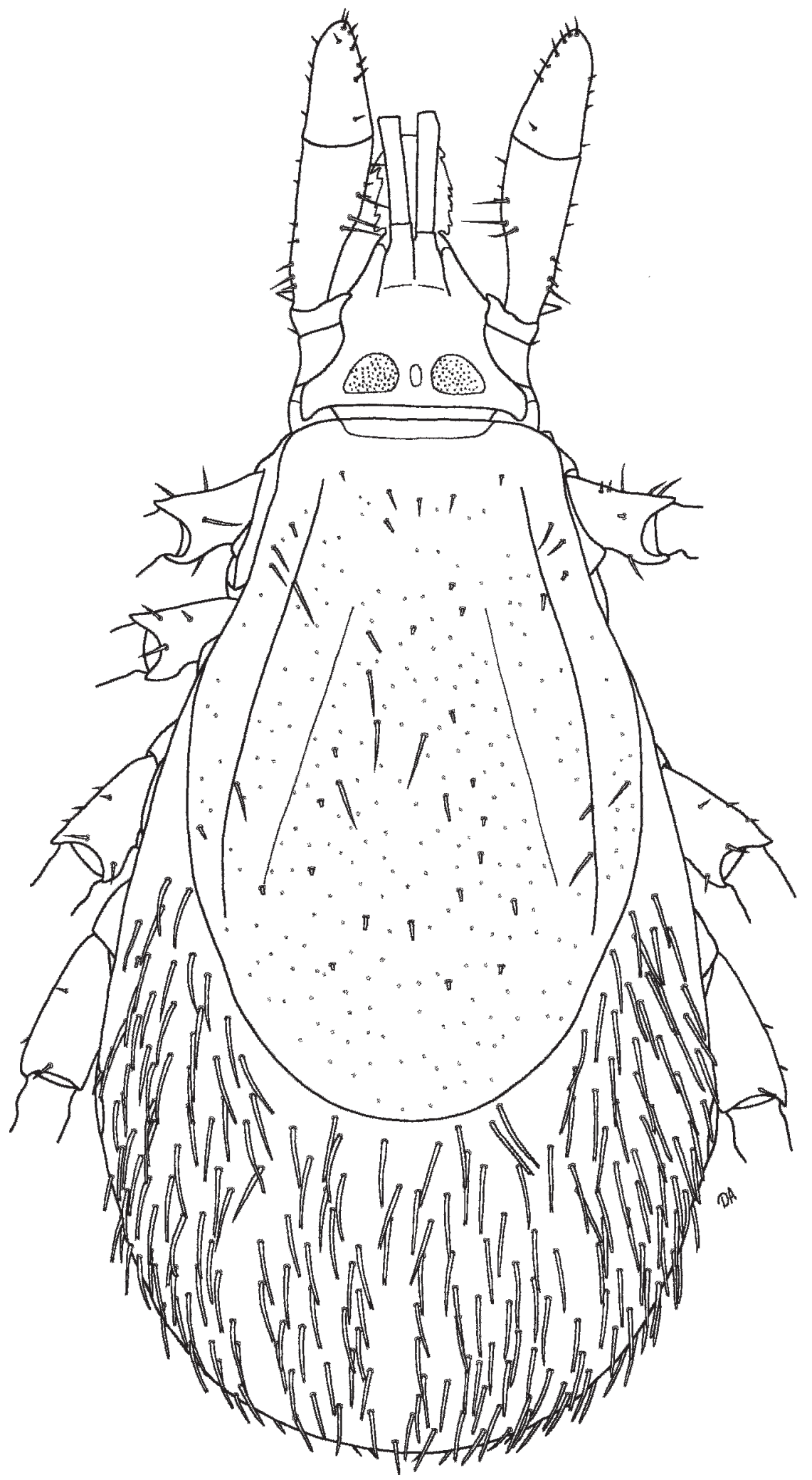

Figure 1. Ixodes (Afrixodes) fynbosensis n. sp., female dorsally. Bar $=1 \mathrm{~mm}$. Leg segments from femur to tarsus are omitted. 


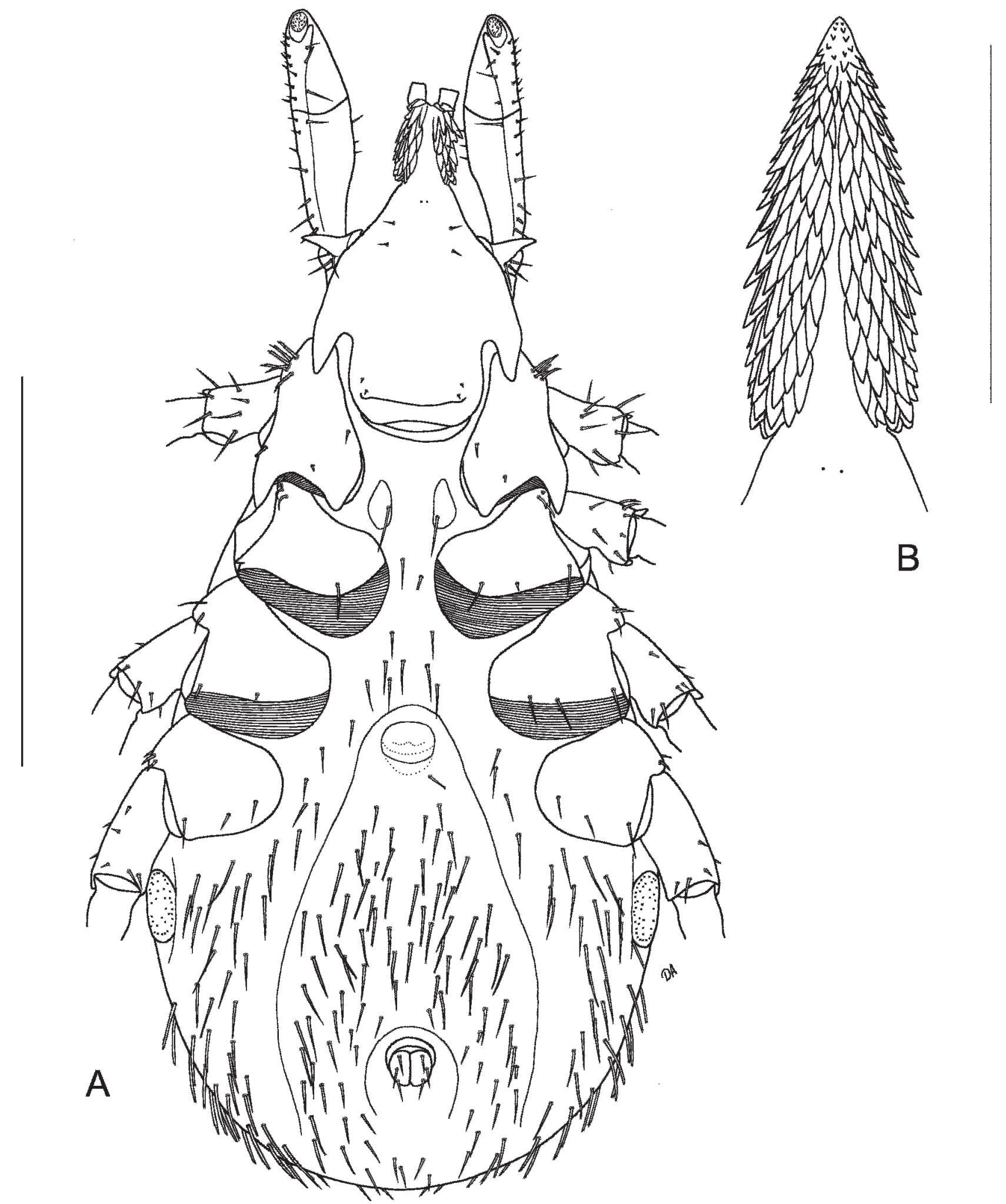

Figure 2. Ixodes (Afrixodes) fynbosensis n. sp., female ventrally. (A) Totally. Bar $=1 \mathrm{~mm}$. (B) Hypostome. Bar $=0.4 \mathrm{~mm}$. Leg segments from femur to tarsus are omitted. 


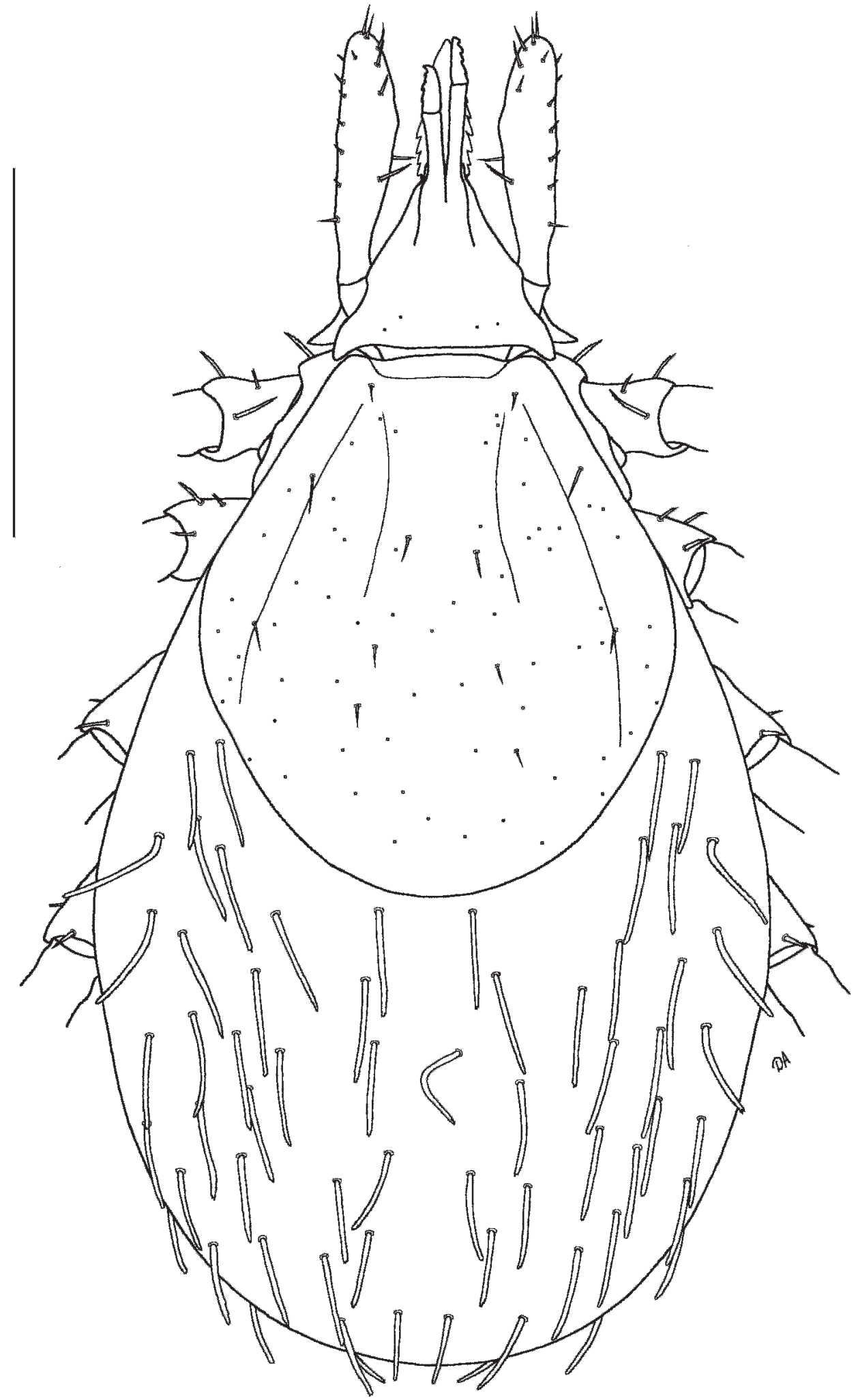

Figure 3. Ixodes (Afrixodes) fynbosensis n. sp., nymph dorsally. Bar $=400 \mu \mathrm{m}$. Leg segments from femur to tarsus are omitted. 


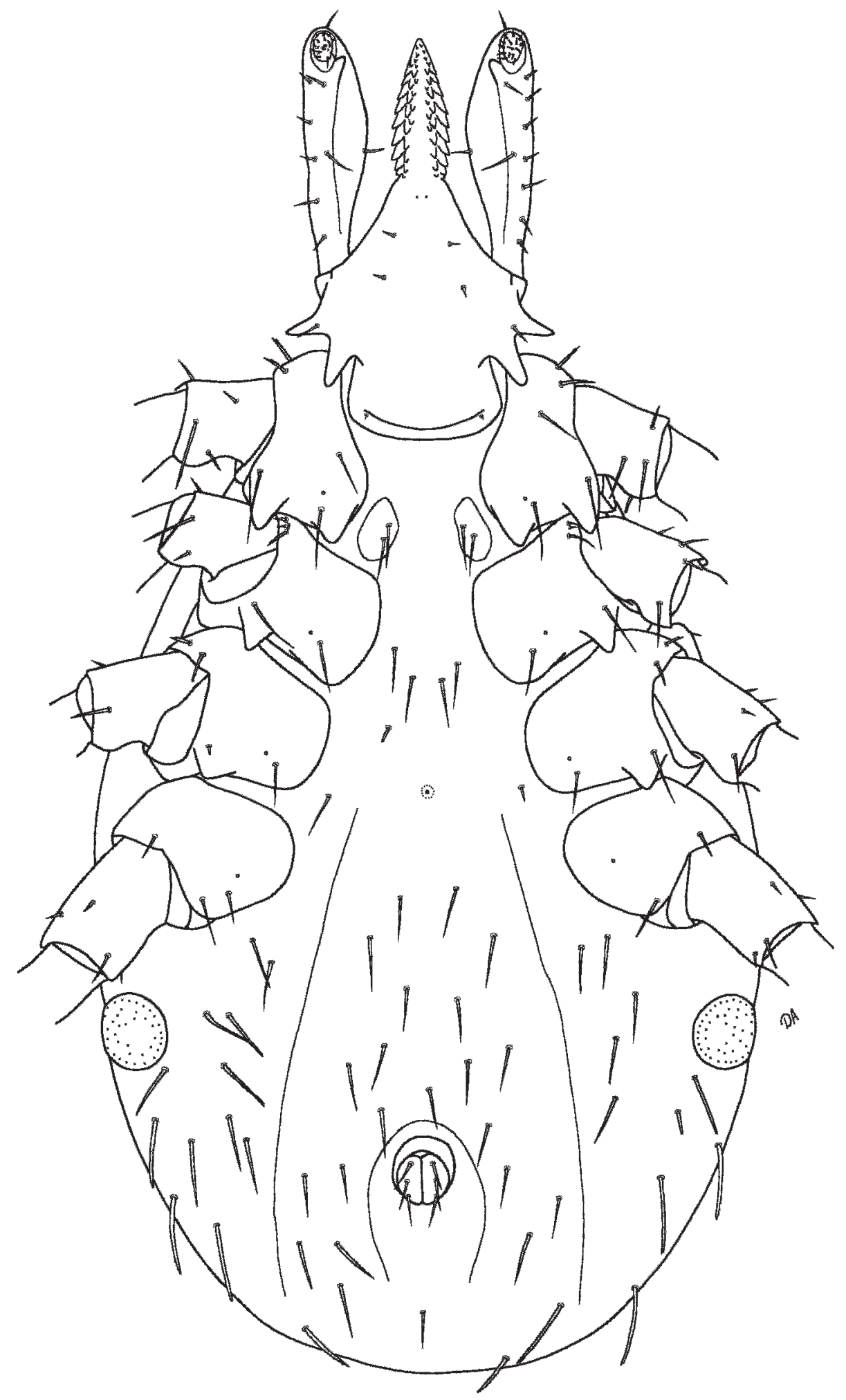

Figure 4. Ixodes (Afrixodes) fynbosensis n. sp., nymph ventrally. Bar $=400 \mu \mathrm{m}$. Leg segments from femur to tarsus are omitted. 
TABLE I. Ixodes (Afrixodes) fynbosensis n. sp., material examined.

\begin{tabular}{|c|c|c|c|c|c|c|c|}
\hline \multirow[t]{3}{*}{2} & & & Domestic dog (1) & Cordoba & December 2004 & C. Keet & RML 124420 \\
\hline & 2 & 25 & R. pumilio (9) & Cordoba & 14 March 2007 & S. Matthee & IGHTC \\
\hline & 20 & & R. pumilio (11) & De Hoop & 8 May 2006 & S. Matthee & IGHTC \\
\hline \multirow[t]{4}{*}{1} & 57 & 213 & R. pumilio (38) & De Rust & 8 October 2003 & S. Matthee & RML 124315 \\
\hline & 6 & 34 & R. pumilio (17) & Jonkershoek & 4 September 2004 & S. Matthee & IGHTC \\
\hline & 4 & 62 & Shrew (2) & Jonkershoek & 1 October 2004 & S. Matthee & IGHTC \\
\hline & 2 & 62 & R. pumilio (18) & Zevenwacht & 3 November 2004 & S. Matthee & IGHTC \\
\hline 3 & 260 & 923 & Total & & & & \\
\hline
\end{tabular}

* L, larvae; N, nymphs.

$\uparrow$ All localities in Western Cape Province, South Africa.

Setae of alloscutum numerous, evenly distributed, length ca. 0.15 , with denticulate apex. Venter (Fig. 2A): As illustrated; small roughly ovoid, paired jugular plates located medially to spur of coxae I, their longest dimension $0.12-0.13$, each bearing 1 seta. Genital aperture medial to posterior margin of coxae III. Genital groove well developed. Anal groove circular with open posterior margin. Setae numerous, length of preanal setae ca. 0.11 , evenly distributed. Spiracular plates: Oval; greater diameter in dorsoventral plane, 0.17. Gnathosoma (Figs. 1, 2A): Length from palpal apices to posterior ventral suture on basis capituli 1.03-1.12, width at level of auriculae $0.54-0.58,1.91-1.93 \times$ as long as broad. Basis capituli (Figs. 1, 2A): Dorsally sub-triangular; posterior margin straight; cornua modest, triangular. Porose areas indented with well-circumscribed borders, separated by a distance slightly less than their own width. Basis capituli ventrally pentagonal; with posterior margin convex; auriculae recurved, long, triangular, tapering to apices. Palpi (Figs. 1, 2A): Elongate, narrow; length (I-III segments) $0.70-0.77$, width 0.15 $0.16,4.63-4.81 \times$ as long as broad, length of segments in descending order, 2, 3, 1, 4; segment I well developed with prominent hook-like dorsomedian spur and sharply pointed, triangular ventrolateral spur; segment II narrow proximally and gradually widening to midlength and nearly parallel sided from midlength to distal end; segment III laterally straight and medially converging to bluntly rounded apex. Hypostome (Fig. 2A, B): Tapering; arising from a medial anterior extension of basis; length 0.46 , width $0.20,2.30 \times$ as long as broad; dental formula approximately 6/6-7/7; denticles sharply pointed. Legs: moderately long, slender. Coxae (Fig. 2A): Coxae I with short triangular posteromedian spur with broadly rounded apex and with long triangular posterolateral spur with tapering apex; posteromedian spur considerably shorter than posterolateral spur; coxae II-IV without spurs, although a thickening at the external angle of coxae IV gives a slight indication of a spur; coxae I-III with syncoxae. Tarsus I length $0.51-0.56$; tarsus IV length 0.50 0.56 .

Nymph (Figs. 3-5): Idiosoma (Figs. 3, 4): Sub-oval, widest just anterior to spiracular plates; length of unengorged or slightly engorged specimens from apices of scapulae to posterior body margin 970-1,360 $(1,182 ; \mathrm{n}=14)$, width $660-960(819 ; \mathrm{n}=14), 1.35 \times-1.59 \times(1.45 \times ; \mathrm{n}=$ 14) as long as broad. Scutum (Fig. 3): Broadly rounded posteriorly, length 501-632 $(584 ; \mathrm{n}=14)$, width 461-564 $(519 ; \mathrm{n}=14), 1.06 \times-1.20 \times$ $(1.13 \times ; \mathrm{n}=14)$ as long as broad; scapulae small, bluntly rounded. Lateral carinae diverging from scapular fields, approximately parallel to lateral scutal margins, reaching posterior scutal margin; cervical grooves faint, commencing as shallow posterior grooves thence diverging slightly. Punctations few, shallow, evenly scattered. Setae 6 pairs, short, slightly longer medially, length 22-46 (31; $\mathrm{n}=15)$. Alloscutum (Fig. 3): As illustrated. Dorsal setae 31-32 pairs, very long; length 90-130 (106; $\mathrm{n}=$ 28). Venter (Fig. 4) as illustrated; small roughly ovoid, paired jugular plates located medially to spur of coxae I, their longest dimension 60-72 $(67 ; n=14)$, each bearing 2 setae. Ventral setae length $40-70(47 ; n=14)$. Anal valves with 3 pairs of setae. Anal groove horseshoe-shaped. Spiracular plates (Fig. 5): oval, greater diameter in dorsoventral plane, $76-87(80 ; n=4)$. Gnathosoma (Figs. 3, 4): Length from palpal apices to posterior ventral suture on basis capituli 384-460 (427; $\mathrm{n}=9$ ), width at level of apices of ventral lateral projections 264-328 (299; $\mathrm{n}=14)$; $1.32 \times-1.49 \times(1.43 \times ; n=9)$ as long as broad. Basis capituli (Figs. 3, 4): Triangular dorsally; posterior dorsal margin straight, slightly indented laterally; dorsal cornua large, bluntly rounded, posterolaterally directed; ventrally lateral projections very long and sharply pointed; auriculae very long, blunt at apices, posterolaterally directed; posterior margin slightly convex. Ventrally 4 pairs of basis capituli setae: 2 pairs of posthypostomal setae; 1 pair of setae at base of ventral lateral projections; 1 pair of setae at posterior lateral corners ventrally. Palpi (Figs. 3, 4): Elongate, narrow; length 244-296 $(277 ; \mathrm{n}=14)$, width $60-72(67 ; \mathrm{n}=$ 14), $3.81 \times-4.60 \times(4.13 \times ; \mathrm{n}=14)$ as long as broad; segment I rudimentary, II and III fused, suture between II and III indistinct; segment I lacking setae, segments 2 and 3 combined with 15 dorsal and 7 ventral setae, segment IV with about 15 setae. Hypostome (Fig. 4): Arising from medial anterior extension of basis, elongate, sharply pointed; denticle-bearing portion length 136-166 (155; n = 9), width $62-67(65 ; \mathrm{n}=6), 2.39 \times-2.51 \times(2.45 \times ; \mathrm{n}=6)$ as long as broad; dental formula $3 / 3$ in anterior $2 / 3$ of length and $2 / 2$ in posterior $1 / 3$ of length; 10 11 denticles in lateral file, $8-9$ in intermedian, 3-5 in median file; apex with 5-9 minute denticles. Legs: Moderate in length. Coxae (Fig. 4): Coxae I with short, blunt, posteromedian spur and moderately long, narrowly blunt, triangular posterolateral spur; posteromedian spur shorter than posterolateral; coxae II-IV lacking posteromedian spurs; coxae II and III with large triangular posterolateral spurs; coxae IV lacking posterolateral spur, but thickening may be present. Trochanters

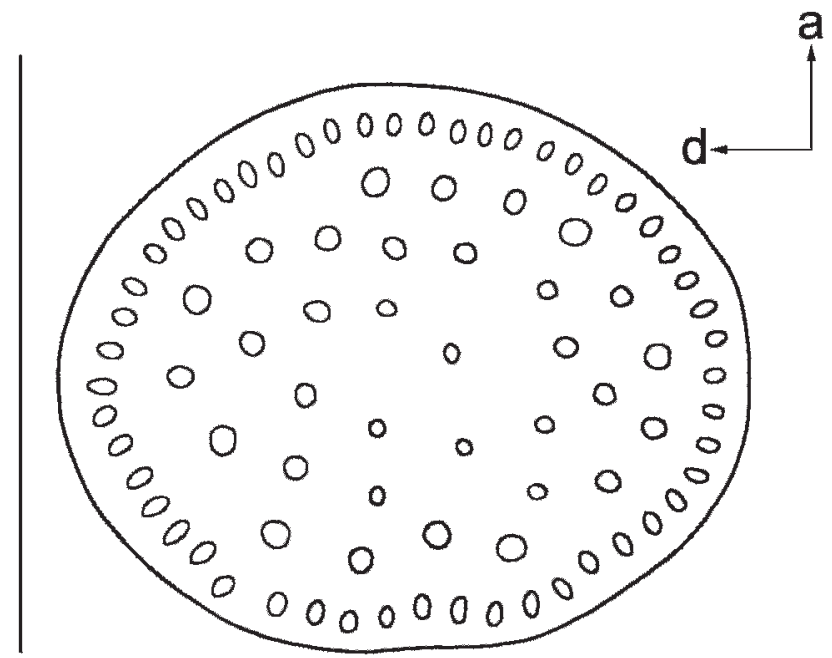

Figure 5. Ixodes (Afrixodes) fynbosensis n. sp., nymphal spiracular plate (a, anterior; d, dorsal). Bar $=100 \mu \mathrm{m}$. 


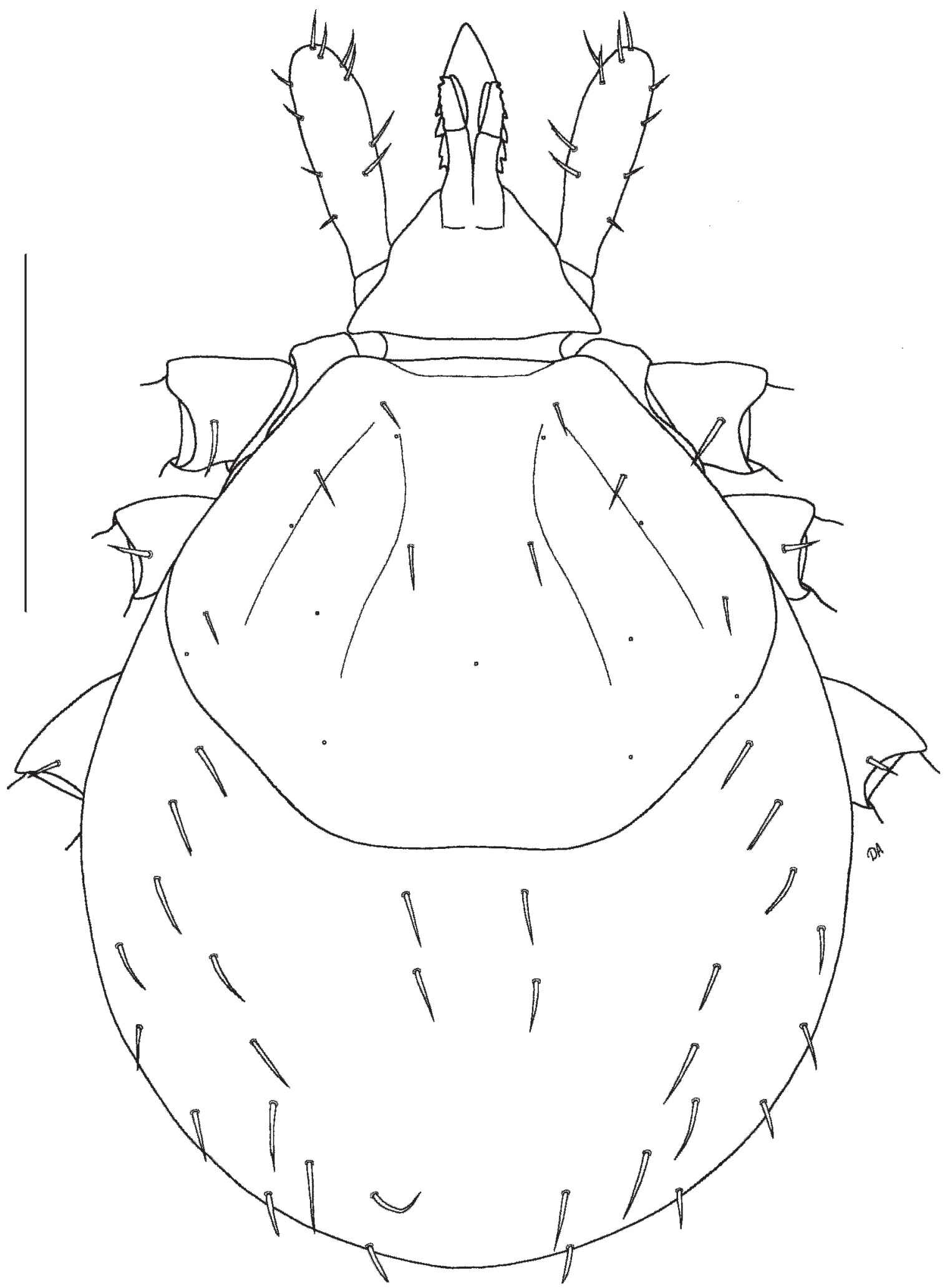

Figure 6. Ixodes (Afrixodes) fynbosensis n. sp., larva dorsally. Bar $=200 \mu \mathrm{m}$. Leg segments from femur to tarsus are omitted. 


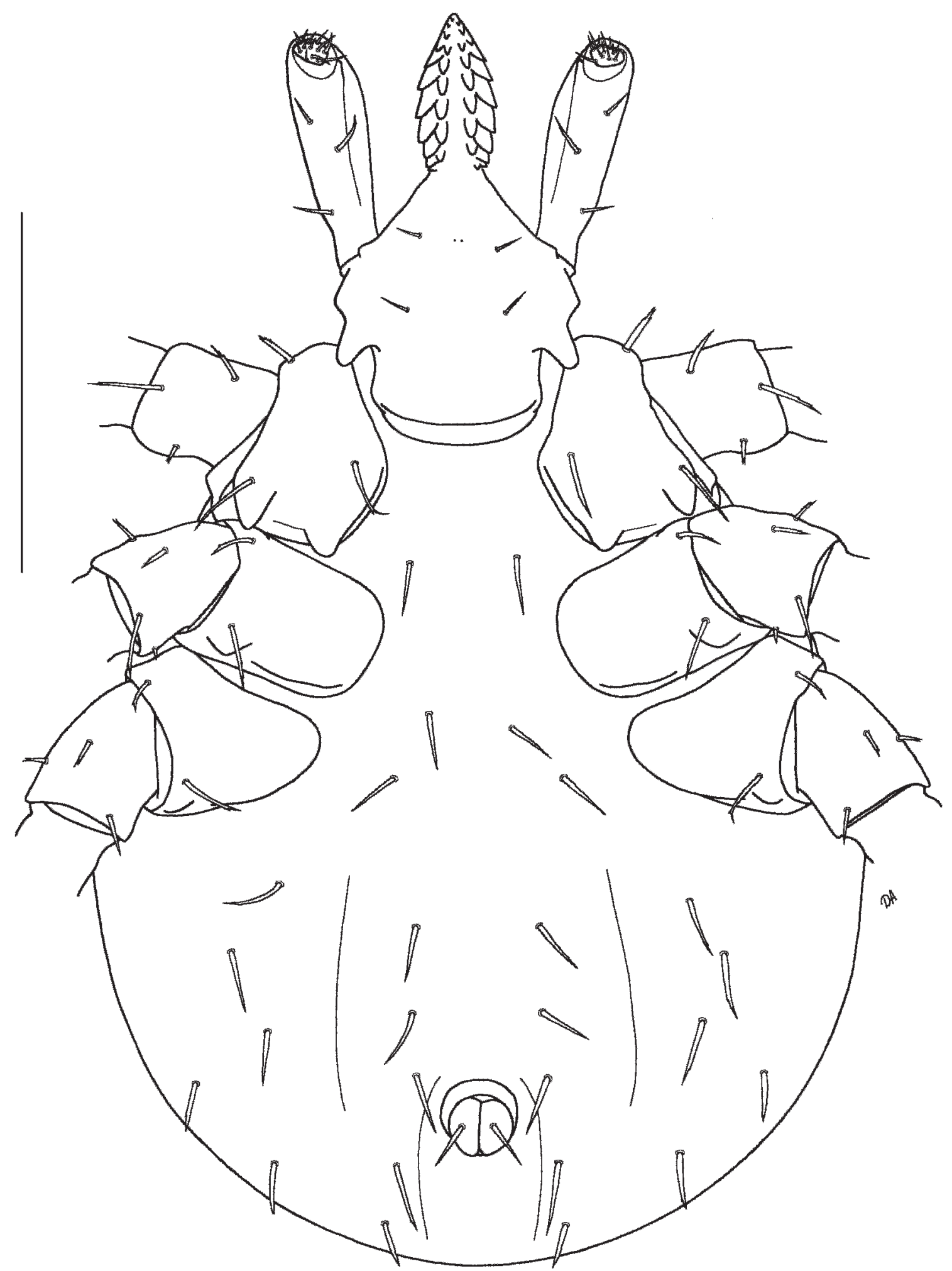

Figure 7. Ixodes (Afrixodes) fynbosensis $\mathrm{n}$. sp., larva ventrally. Bar $=200 \mu \mathrm{m}$. Leg segments from femur to tarsus are omitted 
lack spurs. Tarsus I length 296-340 (321; $\mathrm{n}=13)$, width 76-90 $(82 ; \mathrm{n}=$ $11), 3.73 \times-4.10 \times(3.95 \times ; \mathrm{n}=11)$ as long as broad; tarsus IV length 268-320 (293; $\mathrm{n}=13)$, width $64-72(68 ; \mathrm{n}=2), 4.17 \times-4.19 \times(4.18 \times$; $\mathrm{n}=2)$ as long as broad.

Larva (Figs. 6-7): Idiosoma (Figs. 6, 7): Sub-circular, widest just posterior to coxae III; length of unengorged or slightly engorged specimens from apices of scapulae to posterior body margin 509-588 $(527 ; \mathrm{n}=9)$, width $417-509(439 ; \mathrm{n}=9) ; 1.16 \times-1.24 \times(1.20 \times ; \mathrm{n}=9)$ as long as broad. Scutum (Fig. 6): Length 264-300 (284; $\mathrm{n}=22)$, width 332 $360(344 ; \mathrm{n}=22), 0.79 \times-0.86 \times(0.83 \times ; \mathrm{n}=22)$ as long as broad; hexagonal, posterior margin straight with slight depression, slight posterolateral depressions; lateral carinae parallel to scutal margin; cervical grooves faint, shallow depressions. Setae 4 pairs, $\mathrm{Sc}_{3}$ 20-30 (24; $\mathrm{n}=23$ ); $\mathrm{Sc}_{4} 14-24(19 ; \mathrm{n}=22)$; Alloscutum (Fig. 6): As illustrated. Dorsal setae 15 pairs; 2 pairs of central dorsal, $\mathrm{Cd}_{1} 24-36(31 ; \mathrm{n}=22), \mathrm{Cd}_{2} 24-36$ $(29 ; \mathrm{n}=23) ; 8$ pairs marginal dorsals, $\mathrm{Md}_{1} 30-42(35 ; \mathrm{n}=23), \mathrm{Md}_{7} 24-38$ $(30 ; \mathrm{n}=22) ; 5$ pairs of supplementaries. Venter (Fig. 7): As illustrated; anal groove open anteriorly and posteriorly. Sensilla sagittiformia absent. Ventral setae 13 pairs plus 1 pair on anal valves; 3 pairs of sternals, $\mathrm{St}_{1} 24$ $40(33 ; \mathrm{n}=23) ; 3$ pairs of preanals, $\mathrm{Pa}_{1} 28-40(32 ; \mathrm{n}=23), \mathrm{Pa}_{2} 26-34(31$; $\mathrm{n}=23)$; 4 pairs of premarginals; 3 pairs of marginal ventrals, $\mathrm{Mv}_{1} 30-44$ (36; $\mathrm{n}=21$ ); anal valves with 1 pair of setae. Gnathosoma (Figs. 6, 7): Length from palpal apices to posterior ventral suture on basis capituli $214-240(229 ; \mathrm{n}=17)$, width at dorsal cornual apices $134-152(143 ; \mathrm{n}=$ $23) ; 1.51 \times-1.72 \times(1.61 \times ; \mathrm{n}=17)$ as long as broad. Basis capituli (Figs. 6, 7): Dorsally triangular, with moderate posterolaterally directed cornua; ventrally with short triangular projections directed laterally and slightly posteriorly, auriculae large, U-shaped, directed posterolaterally. Post-hypostomal setae 2 pairs, $\mathrm{Ph}_{1} 16-20(18 ; \mathrm{n}=14), \mathrm{Ph}_{2} 14-20(17 ; \mathrm{n}=$ 10); distance between $\mathrm{Ph}_{1} 36-44(40 ; \mathrm{n}=23)$, between $\mathrm{Ph}_{2} 46-58(51 ; \mathrm{n}=$ 23). Palpi (Figs. 6, 7): elongate, length 134-148 (140; $n=23)$, width $38-42$ $(40 ; \mathrm{n}=23), 3.29 \times-3.84 \times(3.54 \times ; \mathrm{n}=23)$ as long as broad; segment I rudimentary, II and III fused, suture between II and III indistinct; segment I lacking setae, segments II and III combined with 10 dorsal and 3 ventral setae, segment IV with about 12 setae. Hypostome (Fig. 7): Sharply pointed, denticle-bearing portion length 84-98 $(93 ; \mathrm{n}=17)$, width $38-44$ (42; $\mathrm{n}=18), 2.00 \times-2.35 \times(2.22 \times ; \mathrm{n}=16)$ as long as broad; dental formula $2 / 2$ throughout length, 7-8 denticles in lateral file, 6-7 in median file; apex with 4-8 minute denticles. Legs: Moderate in length. Coxae (Fig. 7): Coxae I with moderately large, bluntly triangular posteromedian and posterolateral spurs, posteromedian spur shorter than posterolateral; coxae II with moderate arcuate posterolateral spur, coxae III lacking spur or with small fold-like spur; internal spurs absent but with an indication of slight surface thickening replacing spurs; coxae I with 3 setae, coxae II and III with 2 setae each. Trochanters: Lack spurs. Tarsus I: Length 170-200 $(185 ; \mathrm{n}=20)$, width $60-66(63 ; \mathrm{n}=17) ; 2.73 \times-3.13 \times(2.96 \times ; \mathrm{n}=17)$ as long as broad.

\section{Molecular observations}

Cytochrome oxidase I sequences obtained for the I. fynbosensis nymph and adult stages were identical (confirming the positive association of the description of these 2 life stages). The sequence divergence values between I. fynbosensis and the remaining 10 recognized ixodid species range from a low of $13.7 \%$ (between I. fynbosensis and I pilosus) to a high of $23.2 \%$ (between I. fynbosensis and I. ovatus). The average sequence divergence between $I$. fynbosensis and the remainder of the taxa was estimated at $17.8 \%( \pm 3.3 \%)$, and the sequence diversity within Ixodes (excluding $I$. fynbosensis) was estimated to be $20.1 \%$ ( $\pm 3.6 \%$ ). These data strongly support the recognition of $I$. fynbosensis as a distinct species, and preliminary phylogenetic analyses based on 174 parsimony informative characters indicate that I. fynbosensis is evolutionary, for the taxa included in this study, and is placed as a sister to I. pilosus and I. rubicundus (data not shown). No statistical support, however, could be obtained for this association.

\section{Taxonomic summary}

Holotype: Female, from domestic dog, Cordoba, Western Cape Province, South Africa $\left(34^{\circ} 02^{\prime} \mathrm{S}, 18^{\circ} 50^{\prime} \mathrm{E}\right)$, December 2004, C. Keet; deposited in the USNTC (RML 124420).

Paratypes: Total: 1 female, 57 nymphs and 229 larvae, from Rhabdomys pumilio, Farm De Rust, Western Cape Province, South Africa $\left(34^{\circ} 10^{\prime} \mathrm{S}\right.$, $19^{\circ} 54^{\prime} \mathrm{E}$ ), 8 October 2003, S. Matthee; deposited in the USNTC (RML 124315); 1 female (RML 124420) with the same collection data as for holotype. Some of the paratypes will be deposited in the collections of the Zoological Institute, Russian Academy of Sciences (St. Petersburg, Russia), and the Gertrud Theiler Tick Museum of the Onderstepoort Veterinary Institute (Onderstepoort, South Africa).

Distribution and hosts: The collection data for I. fynbosensis are listed in Table I. This species is confined to South Africa (Western Cape Province). Two females have been collected from a domestic dog. A single female and numerous nymphs and larvae have been collected from four-striped grass rats (Rhabdomys pumilio [Sparrman]). Some immature stages have also been collected from an unidentified shrew taxon belonging to the Soricidae.

Etymology: The species is named for its association with the Fynbos biome of South Africa.

\section{Remarks}

The female of I. fynbosensis is easily differentiated from the other African Ixodes species by the large, tapering, triangular ventrolateral spur on palpal segment I. The female of I. fynbosensis resembles that of Ixodes albignaci Uilenberg \& Hoogstraal, 1969, Ixodes bakeri Arthur \& Clifford, 1961, Ixodes colasbelcouri Arthur, 1957, Ixodes lemuris Arthur, 1958, Ixodes lunatus Neumann, 1907, Ixodes myotomys Clifford \& Hoogstraal, 1970, and Ixodes nesomys Uilenberg \& Hoogstraal, 1969, by its very long auriculae and very long posterolateral spur on coxa I. The new species differs from these species by its short and blunt posteromedian spur on coxa I; this spur is considerably shorter than the posterolateral spur, and it also differs by the absence of a spur on coxae IV. In the other species, the posteromedian spur of coxa I is long and pointed, and it is longer or equal to the posterolateral spur; they also have a small to large spur on coxa IV.

A comparison of the immature stages of Afrixodes is a difficult task because these stages are unknown or undescribed for the majority of species, and, in addition, several of the available descriptions are of poor quality. Nevertheless, our comparison reveals that the nymphs and larvae of I. fynbosensis are most similar to those of I. albignaci, Ixodes ceylonensis Kohls, 1950, and I. colasbelcouri because of their very long auriculae. Nymphs of I. fynbosensis can be distinguished from those of the latter species by a sharply pointed hypostome apex (blunt in I. albignaci) and long and acute ventrolateral projections of basis capituli (very short in $I$. ceylonensis and I. colasbelcouri). Larvae of $I$. fynbosensis can easily be distinguished from these species by only 2 pairs of central dorsal setae ( 5 or 6 pairs in the other species).

It is worth mentioning that the new species was collected together with numerous specimens (females, nymphs, and larvae) of I. bakeri from the same host individuals (Matthee et al., 2007), and that the initial differentiation between the 2 species can easily be made on the basis of the larger size of all stages of development of I. fynbosensis. Larvae and nymphs of I. fynbosensis can easily be distinguished from those of I. bakeri by sharply pointed hypostome and long auriculae (blunt hypostome and short auriculae in I. bakeri); for discrimination between the females of these species see above.

\section{ACKNOWLEDGMENTS}

We thank Cape Nature for permits and assistance with fieldwork and private land owners and managers for involvement in the project. We are grateful to M. van Rooyen, P. le Roux, C. Kassier, C. Keet, and J. Niesing for field and technical assistance. A. Ropiquet provided the sequence of the I. fynbosensis nymph. The field and laboratory work was funded by the National Research Foundation (fellowship to S.M.), University of Stellenbosch, and BIOTA Southern Africa. The participation of I. G. Horak and C. A. Matthee in this project has been supported financially by the National Research Foundation (NRF), and any opinions, findings, and conclusions or recommendations expressed herein are those of the authors; the NRF does not accept any liability in regard thereto.

\section{LITERATURE CITED}

Arthur, D. R. 1965. Ticks of the genus Ixodes in Africa. Athlone Press, London, U.K., 348 p. 
Camicas, J.-L., J.-P. Hervy, F. Adam, and P.-C. Morel. 1998. The ticks of the world (Acarida, Ixodida). Nomenclature, described stages, hosts, distribution. Orstom éditions, Paris, France, $233 \mathrm{p}$.

Clifford, C. M., D. E. Sonenshine, J. E. Keirans, and G. M. Kohls 1973. Systematics of the subfamily Ixodinae (Acarina: Ixodidae). 1. The subgenera of Ixodes. Annals of the Entomological Society of America 66: 489-500.

Folmer, O. M., M. Black, R. Hoeh, R. Lutz, and R. Vrijenhoek. 1994. DNA primers for amplification of mitochondrial cytochrome $c$ oxidase subunit I from diverse metazoan invertebrates. Molecular Marine Biology and Biotechnology 3: 294-299.
Matthee, S., I. G. Horak, J.-C. Beacournu, L. A. Durden, E. A. Ueckermann, and M. A. McGeoch. 2007. Epifaunistic arthropod parasites of the four-striped mouse, Rhabdomys pumilio, in the Western Cape Province, South Africa. Journal of Parasitology 93: $47-59$

Mitani, H., M. Takahashi, M. Masuyama, and M. Fukunaga. 2007. Ixodes philipi (Acari: Ixodidae): Phylogenetic status inferred from mitochondrial cytochrome oxidase subunit I gene sequence comparison. Journal of Parasitology 93: 719-722.

Swofford, D. L. 2002. PAUP*: Phylogenetic analysis using parsimony, and other methods, version 4.10. Software distributed by David L. Swofford, Illinois Natural History Survey, Champaign, Illinois. 